\title{
On the Cultivation of Cross-culture Communication Competence of Second Language Learners
}

\author{
Haiyan Gao \\ School of Foreign Languages, He Ze City, China
}

\begin{abstract}
The main significance of language lies in communication exchanges. English as a kind of language is a tool for people to communicate. At the same time, language is an important and prominent part of culture. The languages of different nations are not only restricted by the social cultures of their own but also reflect their specific cultural content. So to learn the language well, it is necessary to understand the culture. The level of our learning can not be judged just from the mastery of the vocabulary and grammar. English teaching should strengthen the cultural sense education, making clear the relationship among language, culture and teaching. The paper has proposed the necessary conditions to cultivate cross-cultural communication competence and the English teachers' roles based on the current status of English teaching. So it is easily to explore how to guide students to value the input of the second language acquisition and then enhance their basic knowledge of English language, nonverbal communication skills and cross-cultural communication competence.
\end{abstract}

Index Terms-SLA, cultivation, cross-cultural communicative competence

\section{INTRODUCTION}

Culture, in a broad sense, means the total way of life of a people, including the patterns of belief, customs, objects, institutions, techniques, and language that characterizes the life of the human community. As culture is so inclusive, it permeates virtually every aspect of human life and influences predominantly people's behavior, including linguistic behavior. Language is the carrier of culture. Any kind of language reflects its corresponding culture. Over the years, the relationship between language and culture has not been given sufficient attention in English teaching. In teaching practice, it seems that as long as the abilities of listening, speaking, reading and writing are trained, the learners can master the pronunciation, vocabulary and grammar rules and communicate in English influently. In fact, because it is difficult for us to understand the cultural background of the language and the differences between Chinese and western culture, the phenomenon of ambiguity, misunderstanding and pragmatic failures appears frequently. For example, the expression "How much can you earn in a month" represents the interest of foreigners, which violates the privacy of others and will offend the other side. The Chinese people take humility as a virtue. When foreigners praise the talent of a Chinese, the Chinese people usually answer "you are overpraising me", (I'm flattered.) which often makes the speakers feel that you are doubting his judgment. It has repeatedly been found that learners who lack sufficient knowledge about the target culture can hardly become active and appropriate language users in their target language. For these reasons, the information concerning cultural differences has rightly been introduced into language classrooms of different kinds for enhancing learners' cultural consciousness and improving their performance in cross-cultural contexts of communication.

This paper will try to explore the conditions of cultivating the cross-culture communication competence of the second language learners. The thesis consists of six parts. Part one focuses on the previous achievements and studies on the second language acquisition, with the emphasis on the subject matters and approaches. Part two will focus on the relationship between the language and culture. Language not only reflects culture but also is part of culture. Part three states the principles of culture-guiding. With these principles, the culture study could be guided more scientifically. The fourth part serves as the main body of this paper which concerns the conditions of cultivating the cross-culture communication competence. The last part tells the role of the teachers. Their helps will be very helpful.

\section{LITERATURE REVIEW}

When globalization becomes a fact, the importance of cross-cultural communication is further highlighted. On the one hand, different countries and cultures are interacting with each other more than any times. On the other hand, it is observed that more and more miscommunication occurs in international society. Carl Rogers (1961) a great psychologist, states that real communication takes place when we listen with understanding. By analogy, it may be equally said that communication collapses when people listen with misunderstanding. More specifically, it may even be stated that cultural stereotypes and conflicts come in when speakers communicate with no real understanding. As is well 
known, language plays a decisive role when we communicate with others but the diversity in language and culture makes cross-cultural communication a highly risky mission. The domestic second language acquisition and second language / foreign language teaching and research scholars explored the inspiration the main theories of second language acquisition give to our language teaching, the application problems of the research findings of second language acquisition in language teaching and the mutual relationship between theories and application from the macro point of view. Meanwhile, they discussed the inspirations and directive significance of the theories and models of second language acquisition to the teaching of all the language skills in the micro point of view. Mr. DaiWeidong and ShuDingfang explored the main factors that affect foreign language learning, contrastive analysis, error analysis, interlanguage and communicative strategies systematically based on the inspiration of the second language acquisition theories. Mr. WangChuming tried to design foreign language well according to their learning characters and study environment. But the cultivation of culture in cross-culture communication of the second language learners is not paid much attention to. This thesis will discuss the conditions to cultivate the competence of cross-culture communication of the second language learners which may help the learners to study the foreign language better.

\section{IMPORTANCE OF THE CUltivation OF CROSS-CUlture COMMUNiCATION COMPETENCE}

Language and culture has always been an inseparable unity. Language contains extremely rich cultural connotations, which not only have the history and culture heritage, but also mirror the reality of the culture (Zhang, 2007). Language itself is the product and component of culture. Also is the carrier of culture, which mutually penetrates and interacts with culture. Language reflects the characteristics of a nation, including its history and cultural background, people's thinking models, social behaviors and social ways. Some sociologists say that language is the cultural keystone - there is no culture without language. Meanwhile, language reflects and is restricted by culture.

The relationships between language and culture have widely been acknowledged. When it comes to language teaching and learning, the influence of cultural knowledge on the linguistic performance of language learners has been identified and highlighted. The English teaching syllabus of our country explicitly requires that: "teaching activities should be conducive not only to the training of language skills but also to communicative competence. The activities should not only attach great importance to language training on the sentence level, but also gradually develop the communicative competence on the discourse level." That is to say, the purpose of teaching and learning in language teaching activities includes not only the basic language knowledge --- pronunciation, vocabulary and grammar but also the competence of communication appropriately with these basic knowledge. For a long time, there is a common phenomenon in English learning that the students strive to remember a lot of words, phrases and grammar knowledge, do many exercises, and then take and pass various tests. But once they come into the language context, most people feel that their communicative competence is poor. This shows that great importance has to be attached to the cultivation of the students' actual listening and speaking abilities, particularly in terms of cross-culture communication competence should be valued and strengthened.

Because of the cultural differences, foreign language learners in the learning process may face such situation: they know every word appearing, but they can not understand the meaning of a phrase or sentence case. For example: "Every dog has his day". Learners whose native language is Chinese may be difficult to comprehend the meaning. In fact, if one knows well the culture of the English-speaking countries, they may know that in English, dog's image is generally not bad. It often refers to individuals. The meaning of the sentence is: Everyone has his day.

Similarly, the English people learning Chinese may also make cultural deviations and errors due to the culture difference. For example, they can not understand why those people who are very successful and popular can be described as “红的发紫”. In fact, “红” and “紫” here do not mean the color of "red" and "purple", but rather refer to popularity and very popular. As to why it is expressed in this way, it is difficult for any one to explain clearly. It has become part of the whole system of Chinese and Chinese culture. Therefore, language learning can not be confined to pronunciation, grammar, vocabulary, idioms and other language systems themselves. We should learn from the native people how to look at things, how to observe the world and how to use language to reflect their thoughts and behaviors.

\section{PRinciples of Cultivation of Cross-Culture Communication COMPETENCE IN TEACHING}

The leading-in of culture communication is to master and use language easily. Language is used for communication in vocal or non-vocal forms. Language is the product of culture, and the principle of cultivation of cross-culture communication competence is to respect the distinctive cultures of different countries and regions. Therefore, culture knowledge should be put into the first place. It can not only enhance the understanding of language but also accurately grasp the background of language use. So it is necessary to strengthen the teaching and explanation of culture involved. Of course in language teaching, the leading-in of culture should follow some principles:

\section{A. Principle of Unity}

Language and culture has always been an inseparable unity. Language is the carrier of culture. Culture cannot exist without language; the language can also not be divorced from the culture. So to learn the language well, the leading-in of culture should run through the language teaching. Language and culture should be unified. 


\section{B. Principle of Difference}

Language reflects the corresponding culture of a nation. Different nation has different culture, especially the culture of eastern and western countries. Therefore, in the process of the second language learning, teachers should always remind students that the understanding of language should be based on the level of cultural understanding, especially bearing in mind that the national culture can not be used indiscriminately on other languages. Otherwise it is likely to cause unnecessary trouble and misunderstanding. The students should gradually develop cross-cultural awareness and promote the ability of language use.

\section{Principle of Objectivity}

Cultures are only different in content. It cannot be said that the culture of one kind of language is good or bad. It is necessary to take the principle of objectivity when imparting and using language. Firstly, the teachers can not compare subjectively the merits of cultures and influence the students with this point of view. What's more, the students cannot use their own or others' subjective ideas to understand one kind of culture when they accept the new culture information. In order to truly realize the cross-culture communication, we have to avoid the subjectivity, one-sidedness and arbitrariness on the understanding of culture.

Culture competence should be cultivated on some specific conditions and environment. Next chapter will elaborate these elements.

\section{CONDitions For Cross-CULTURE COMMUNiCATION COMPETENCE}

\section{A. Basic English Language Skills and Non-verbal Ability}

HuWenzhong (1999) said: "The communicative competence will be like a tree without root if they are not based on language competence."(p.62) The second language acquirers are often good at vocabulary and grammar. However, they are short of pronunciation. Even if they make it through constrainedly, once they enter into the actual communication, they cannot speak influently and smoothly enough. Although their heads are full of words, they do not know how to start in oral communication. On the other hand, the second language acquirers have little opportunities to communicate in English in our daily life. So the level of oral communication can be imagined.

The non-verbal ability generally refers to the body language .It is a kind of language with the actions of our body parts to convey information. According to the study, the expression of non-verbal communication accounts for $70 \%$ of our daily communication (Wen, 2003). Visibly, the role of non-verbal expression should not be underestimated. But the second language learners are rarely involved in this kind of knowledge. It can easily lead to communication errors. The same figure gesture may have different meanings in different countries. For example, if the thumb and index finger are rung to the shape of "0", it is an expression of praise in the United States but contempt and disdain in France. Different cultures have so many interpretations to this gesture. If the language learners do not understand these, how can they have the successful communications?

The basic English language skills and non-verbal ability reinforce each other. They jointly contribute to a successful communication.

\section{B. Knowledge of Traditional Culture and Customs}

Culture is a very broad concept which penetrates the field of religion, law, morality, customs, traditions, politics, economy and other aspects in our society. To really learn a language well, one must know the rich cultural deposits and traditional customs involved in the target language. For example, it is a long history of China to be modest while it is the principle of Americans to be frank. Based on different cultural backgrounds, the hospitable Chinese masters would deny the praise of the American guests modestly when they invite the American friends to come to their homes; In the case of hunger the Chinese will refuse to eat much out of courtesy and hospitality in American friends' home. In this case, the reason of misunderstandings does not have anything with the communicators' pronunciation, words use and sentence-making. Thus, the simple vocabulary, grammar and voice are not enough for the successful communication. The second language learners should also strengthen the learning of the traditional culture of the target language, and thus grasp the language on the whole.

\section{Certain Knowledge of Social Pragmatic Communicative Principles}

According to Austin's Speech Act Theory (1975), a speaker might perform three acts simultaneously when speaking: locutionary act, illocutionary act, and perlocutionary act. Locutionary act is the act of conveying literal meaning by means of syntax, lexicon and phonology. Illocutionary act is the act of expressing the speaker's intention; it is the act performed in saying something. Perlocutionary act is the consequence of, or the change brought about by the utterance. If the listener does not work according to the speaker's intention, that is to say the illocutionary acts do not happen, it will lead to communication failure. The communicators should be adept at comprehending the deep meaning of words and response according to the situation.

Grice's Cooperative Principle (1975) suggests that the successful communication should observe the following four criteria: the maxim of quantity, the maxim of quality, the maxim of relation, the maxim of manner. Sometimes, however, in order to achieve a particular purpose, the communicators will deliberately violate the four criteria. They will response 
to the speaker's illocutionary acts implicitly. Such as the following dialogue:

A: The boy is an unwelcome guest.

B: Well, ah, it is a fine day today.

In this dialogue, B said something irrelevant to A's question. It is apparently to violate the maxim of relation. However, this deliberately lacking of cooperation has intimated an illocutionary act: he did not wish to comment on this topic. Therefore, understanding certain social pragmatic principles will contribute to the successful communication among people of different social culture.

\section{Ability of Roles Transition}

In our daily communication, different people have different social roles in different situations. Everyone should be good at transiting their roles depending on the circumstances. It is necessary to overcome ethnocentrism, ethnic prejudice. Meanwhile, the learners have to prevent the blind copying regardless of the situation. "When in Rome, do as the Romans do." In the process of Cross-cultural communication, our students need to develop their own sense of cross-cultural communication, distinguish their own cultural environment, and then transform the role correspondingly.

\section{Roles of Teachers in the Cultivation of CROss-Culture COMmunication Competence}

Teaching is a complex project. The teaching effect depends largely on the teaching ways of the teachers. In teaching activities, teachers should not only act as directors to guide students to participate in classroom activities but also have the abilities to perform to attract students to follow the teachers. Recently the national reform of English teaching has also proposed that teachers should improve the cultivation of the students' abilities of listening and speaking through communicative-based teaching model. In order to realize the purpose, the teachers should obey the following aspects.

\section{A. Encouraging and Cultivating the Students' Interests}

Strong interest and motivation are driving forces for success. For a considerable number of students, English language learning is time-consuming and boring. The reason is that the effect of language learning is not obvious in a short term. The students cannot get the sense of accomplishment which thus affects the learner's interest in learning.

To stimulate the interests of students, teachers should strengthen the communication with the students, realizing the difficulties they face, helping them to establish the confidence. For example, teachers in their class tell some inspiring stories and convey the message that: there is no shortcut to language learning for cultural communication, and only those who pay more efforts will reap more. Or teachers could choose some students who have a high proficiency in English study, and make reports for class. Then students will discover that learning models are around, and the face-face communication will strengthen the autonomous learning awareness and promote their learning enthusiasm. In this way, students can have enough interest to learn the basic culture knowledge out of the basic language knowledge of English and strive to improve their listening and speaking levels. They can actively participate in classroom activities, and fully display their merits. Therefore, teachers' encouragement has a great impact on students' learning interest.

\section{B. Giving the Students Reasonable Guidance and Input}

According to Krashen's Input Hypothesis (Krashen, 1985), learners advance their language learning gradually by receiving "comprehensible input". He defined comprehensible input as " $i+1$ ", i represents learners' current state of knowledge, the next stage is a $\mathrm{i}+1$. This indicates that the information the teachers input to the students should be acceptable to the students. It cannot be so excessive to impede the input of the knowledge; neither can it be very little to make the students boring. Language is the carries of culture. Culture was contained in language. In language teaching, teachers may supply the relevant cultural knowledge for the students according to different study contents to strengthen the culture guide in language input. And require the students to recite the cultural notes in their own words or work in pairs. In this way, student's knowledge on different cultures will be solid. Using comparison method, guide their attention to the cultural difference between western and Chinese culture to enhance their understanding of basic language knowledge and the cultivation of the sense of the cross-culture communication. For example, teachers could start the lesson of color meanings between China and western countries by presenting some real instances. We choose the "green" color as an example. In China, green is the color of new hope and life, so is in western cultures. But there is an exception that is "a green hat". Western cultures take it easy to take a green hat or red hat, nor of it in China. In oriental cultures, "a green hat" means that a man's wife has an affair with other man, so it is a humbling matter to an honorable man. Another example is the black leather shirt. In diplomatic event, ladies are forbidden to wear the black leather shirt, because in western cultures that costume is the symbol of prostitute (hooker). Anyone who wears black leather shirt to other foreign countries will be laughed and suspected. Furthermore, to facilitate the absorption of knowledge, teachers can use English films, television, video and other multi-media teaching methods to make the culture input more visual and understandable. In class teaching, teachers will guide students to heed some culture elements while watching, or ask some to detect the cultural difference between China and western countries, or ask them to show their own voice on cross-culture competence. In this way, students are immersed in culture knowledge and will have a clear mind on culture awareness cultivation.

\section{Assessing the Students Reasonably}


The teachers' evaluation of students can significantly affect the students' interest in learning. This is especially important for oral expressions. Most linguistic experts thought that in communicative activities, errors are natural. Students are tolerant to make errors. However, some few experts argued that if the students received only positive feedback and lacked negative feedback or error correction, then the students will lose recombination mechanism of the brain. The previous incorrect input will be a fossil which can no longer be corrected. Thus, teachers should make a reasonable assessment for the students. They cannot just give positive feedback to the students due to the concern that the enthusiasms of the students are attacked. Meanwhile, the teachers cannot correct all the errors which may make the students feel too nervous and worried to open their mouths and affect the improvement of their communicative ability. For example, teachers should make positive assessment to some introversive students. As teachers' encouragement and positive remarks are the driving forces for their study. Once they have overcome their worry in language learning, they will be confident to accept right or wrong. While for those extroversive students, teachers' negative assessments are more meaningful. They lack the carefulness in learning and take every mistake as natural. For those students, a sharp criticism is more practical for them. In short, teachers should be good at evaluating different students in different situations and guiding students to judge themselves correctly. Encourage them to avoid weaknesses in the study and enhance the strong points.

\section{CONCLUSION}

Language is the carrier of culture. Language can not be divorced from culture. The significance of language learning lies in communication. Learning and communication integrate with each other. The world is a global village and no country or people will be isolated from others. On the cross-culture communication competence, learners and teachers both should share some responsibility. On the one hand, in language learning, the learners should be fully aware of cultural factors on the learning effect. By means of the input of the culture of the target language, the learners can enhance the overall understanding of the language. On the other hand, with the development of the integration of the world and more and more cross-cultural communication exchanges, language learning should liberate from the "dumb foreign language". Thus, the students should make full use of the conditions of cultivating the cross-culture communication competence. Strive to advance the basic English language skills and non-verbal ability. Master the knowledge of traditional culture and customs. Learn certain knowledge of social pragmatic communicative principles and train the ability of transiting roles. The basic element in communication is to respect each culture and adhere to the maxims of communication. Meanwhile, the teachers should play great importance in language and culture teaching. Teachers should encourage and inspire the students, and offers great help in their language study. And then give them the reasonable guide and assessment and try to make the assessment reasonable and applicable. In class teaching, teachers should make the class culture involved, and make students experience the cross-culture communication and cultivate the cross-culture awareness. As long as students and teachers put in the same efforts and interest, cross-culture communication competence will surely be improved.

\section{REFERENCES}

[1] Austin, J. L. (1975). How to Do Things with Words. Britain: $2^{\text {nd }}$ ed. Oxford: Clarendon Press.

[2] Grice, H. P. (1975). Syntax and Semantics 3: Speech Acts. New York: Academic Press.

[3] Krashen, S. D. (1985). The Input Hypothesis: Issues and Implications. London: Longman.

[4] Rogers, Carl R. (1961). On Becoming a Person: A Therapist's View of Psychotherapy. Boston: Houghton Mifflin Company.

[5] Hu Wenzhong. (1999). An Introduction to Intercultural Communication. Beijing: Foreign language teaching and research press.

[6] Wen Qiufang, Wang Lifei. (2003).Empirical Study of English Learning Strategies. Shan'xi: Shan'xi normal university press.

[7] Zhang Rude. (2007). Word Form and Meaning Identification. Yunnan: Yunnan university press.

Haiyan Gao was born in Linyi, China in 1983. She received her Master. Degree in English language and Literature from Liaocheng University, China in 2009.

She is currently an instructor in the School of Foreign Languages, Heze University, China. Her research interests include English language and literature, text translation, and English teaching. 